\section{Original Research}

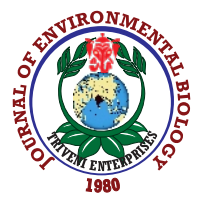

DOI : http://doi.org/10.22438/jeb/41/2(SI)/JEB-22
Journal Home page : www.jeb.co.in ^ E-mail : editor@jeb.co.in Journal of Environmental Biology

p-ISSN: 0254-8704

\title{
Determination of olive cultivars by deep learning and ISSR markers
}

\author{
M. Sesli ${ }^{1}{ }^{*}$, E.D. Yegenoğlu' and V. Altıntas ${ }^{3}$ \\ ${ }^{1}$ Manisa Celal Bayar University, School of Tobacco Expertise, Akhisar, Manisa, 45200, Turkey \\ ${ }^{2}$ Manisa Celal Bayar University, Alasehir Vocational School, Alasehir, Manisa, 45600, Turkey \\ ${ }^{3}$ Manisa Celal Bayar University, Akhisar Vocational School, Akhisar, Manisa, 45200, Turkey \\ *Corresponding Author Email : meltem.sesli@cbu.edu.tr
}

\section{Abstract}

Aim: The aim of the study was to make accurate estimation of olive varieties by using morphologic characters through deep learning and genetic characters through ISSR (Inter Simple Sequence Repeats) markers.

Methodology: In this study, 800 leaf samples were collected from olive varieties and training and testing was performed; 600 samples were assessed for the training process and 200 samples were assessed for the testing process. Convolution of neural networks is a component of deep learning which is used frequently in image processing was used in this study.

Results: Based on the results of such classification, the designed model was successful at a rate of $89.57 \%$ and it was also determined that this structure can be used in the area of problem.

Interpretation: The success of convolution neural networks in terms of classification was exhibited. In ISSR method, the evaluation was performed on the basis of DNAs, i.e., genetic properties of varieties by means of ISSR markers.

Key words: Deep learning, ISSR markers, Neural networks, Olive cultivars

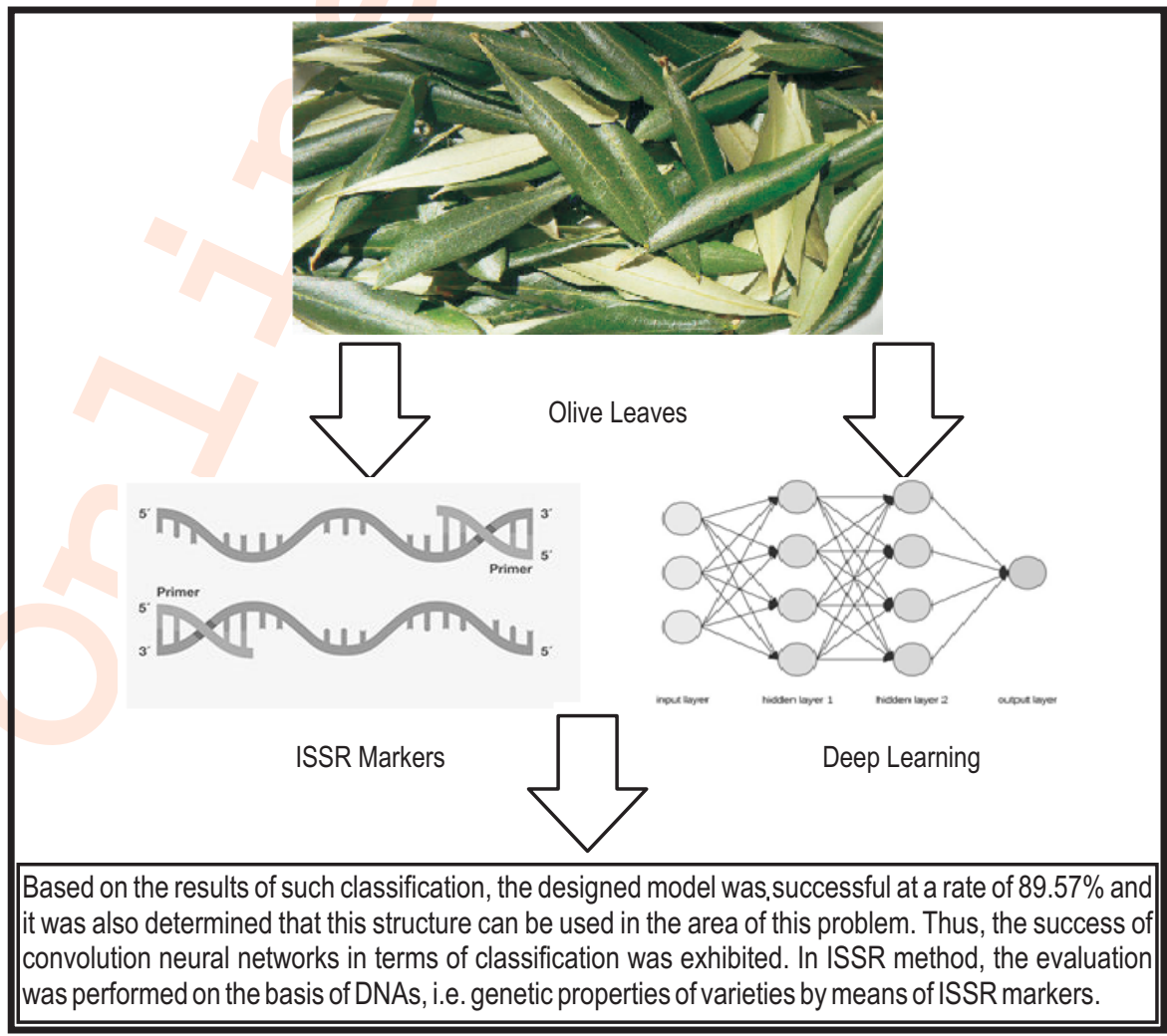

How to cite : Sesli, M., E.D. Yegenoğlu and V. Altıntas: Determination of olive cultivars by deep learning and ISSR markers. J. Environ. Biol., 41, 426-431 (2020). 


\section{Introduction}

Olive (Olea europaea L.) is native to Upper Mesopotamia and South Asia Minor, including South-east Anatolia Region. Olive spread to other parts of the world via three routes, Culture type olives spread from Anatolia to Syria, Palestine, Jordan and Egypt and then to other countries in the Mediterranean Basin. It was first cultivated and bred by the Sami. Archeological works show that olive cultivation dates back to 4 B.C. (Marmarabirlik, 2019).

Olive belongs to family Oleaceae that contain approximately 30 genus and 600 species. Cultivated olives belong to Olea genus, europaea species and sativa subspecies and it spread around the Mediterranean. It is assumed that Olea europaea derived as a result of differentiation of its properties and passing from generation to generation automatically (IOOC, 1997).

Turkey is accepted as one of the origin centers of olive and it is highly rich of olive diversity. In total, 89 genotypes have been reported and registered in surveys performed by the Olive Cultivation Research Institute since 1968 (Çetin et al., 2017).

It is known that some of the olives are not named correctly and this causes confusion in identifying varieties in connection with the high diversity of olives and the fact that some olive varieties resemble each other and same varieties are cultivated in different environmental conditions (Vergarı et al., 1996). In order to solve this problem, both morphologic and genetic characters can be used together (Henry, 2001; Ovesna et al., 2002).

Deep learning model may be used for identifying varieties based on leaf (morphologic) characters (Doğan and Türkoğlu, 2018). Recently, Deep learning has been a popular approach that has improved in terms of accuracy and success in machine learning and artificial intelligence development. Many academic or private studies solve problems such as image classification, speech recognition, object recognition, error detection, video analysis and natural language transactions by using deep learning algorithms.

Although first studies on deep learning date back, it is used successfully because of the number of data that is increasing gradually today. Many data is recorded with the help of electronic devices, sensors, etc., that we have been using in every field of our lives. It has become easier to keep the data collected by such devices in a server, process such data and draw a conclusion. The data structure that has been increasing all the time in the recent years has created another area called the Big Data. Another reason why deep learning is used commonly is the development of hardware called GPU (Graphic Processing Unit) ensuring that the processes are performed more rapidly. Convolutional neural networks algorithm is the most commonly used deep learning method and it is distinguished in feature extraction and classification works (Sakib et al., 2019). This algorithm is influenced from human visual cortex and learns the hierarchy of visual attributes. Low level attributes are learned in first layers, while high level (some parts of object) attributes are learned in increased layers (Karahan and Akgül, 2016).

ISSR markers are used in the identification of olive genotypes via DNA based molecular marker techniques (Yegenoğlu et al., 2017). ISSR method is based on random distribution of nucleotide units such as 2, 3, 4, 5 repeated in eukaryotic genomes, independent of locus and has high repeatability that is effective in the determination of genetic diversity (Zietkiewicz et al.,1994; Gupta et al., 1994; Reddy et al., 2002).

Genetic similarities were determined and classified by UPGMA (Unweighted Pair Group Method with Arithmetic Mean) dendrogram (Sneath and Sokal, 1973) and Simple Matching Similarity coefficient Sokal and Michener (1958) through ISSR markers on the basis of genetic properties (DNA) of same olive varieties. FAMD (Fingerprinting Analysis with Missing Data) 1.31 Schlüter and Harris (2006) program was used for data analysis.

\section{Materials and Methods}

DNA extraction of four cultivated type olives (Domat, Edremit, Gemlik and Uslu): DNA samples were extracted by the method of Doyle and Doyle (1987; 1990). Plant tissues were frozen with liquid nitrogen and then ground in mortar. Seven hundred microliters of preheated extraction buffer $(2 \%$ CTAB (Cetyl trimethylammonium bromide), $20 \mathrm{mmol} \mathrm{I}^{-1}$ EDTA (Ethylenediaminetetraacetic acid), $1.4 \mathrm{~mol} \mathrm{I}^{-1} \mathrm{NaCl}, 100 \mathrm{mmol} \mathrm{I}^{-1}$ Tris- $\mathrm{HCl} \mathrm{pH} \mathrm{8.0,2 \%} \mathrm{mercaptoethanol)} \mathrm{added} \mathrm{on} \mathrm{tissues} \mathrm{in} 1.5 \mathrm{ml}$ Eppendorf tubes and mixed several times by gentle inversions. Samples were incubated for $30 \mathrm{~min}$ at $65^{\circ} \mathrm{C}$. After t cooling down of samples, $700 \mu$ l of cold chloroform: Isoamyl alcohol (24:1) was added to tubes. Tubes were centrifuged for $10 \mathrm{~min}$ at $10.000 \mathrm{rpm}$ $\mathrm{min}^{-1}$ in a refrigerated centrifuge (Nuve $1200 \mathrm{R}$, Izmir, Turkey). Supernatants were transferred into new tubes; $600 \mu$ l of cold chloroform: isoamyl alcohol (24:1) was added and mixed for 5 min. Samples were spun for $10 \mathrm{~min}$ at $10.000 \mathrm{r} \mathrm{min}^{-1}$ again and supernatants were taken into fresh tubes including $10 \mathrm{M}$ ammonium acetate and $3 \mathrm{M}$ sodium acetate; $500 \mu \mathrm{l}$ cold isopropanol was added and mixed for DNA precipitation. Precipitated DNA was removed and washed with $70 \%$ ethanol. DNA samples were dried and re-suspended in TE buffer (TrisEDTA buffer) and RNAase was added (Doyle and Doyle 1987; Doyle and Doyle, 1990; Sesli and Yegenoglu, 2017).

PCR and gel electrophoresis: Amplifications of samples were performed by using ISSR primers. ISSR amplification reactions were carried out in $25 \mu$ l volume containing $25 \mathrm{ng}$ DNA, $4 \mu \mathrm{l}$ primer, $2.5 \mu \mathrm{l} \mathrm{PCR}$ buffer, $2 \mu \mathrm{l}$ dNTP (deoxyribonucleotide 
triphosphate ) stock and $0.5 \mu \mathrm{l}$ Taq DNA polymerase. Annealing temperatures were determined based on the melting temperatures of ISSR primers. The amplification reactions of ISSR were carried out by following these steps: Initial denaturation at $94^{\circ} \mathrm{C}$ for $5 \mathrm{~min}$; followed by 45 cycles at $94^{\circ} \mathrm{C}$ for $30 \mathrm{sec}, 52^{\circ} \mathrm{C}$ for $45 \mathrm{sec}$ and $72^{\circ} \mathrm{C}$ for $2 \mathrm{~min}$, and a final extension at $72^{\circ} \mathrm{C}$ for $5 \mathrm{~min}$. Seven ISSR primers were used from University of British Columbia, 1995). Tubes with PCR reagents without genomic DNA were used as controls. The ISSR-PCRs duplicated and only scorabe bands were used. Agarose-gel-electrophoresis was performed for segregating DNA fragments that were reproduced following $P C R$. Electrophoresis was performed in 1 X TBE (Tris-Boric Acid-EDTA) buffer with 1.2\% agarose gel for ISSR products. Ethidium bromide was used for DNA staining, and was added to gel (Sesli and Yegenoglu, 2017).

Deep learning: Deep learning is one of the machine learning methods and in fact, it is composed of multi-layered Artificial Neural Networks. Deep learning method was developed as a result of the increase in layers in artificial neural networks and it is distinguished since depth has increase because of the increasing quantity of data, the speed of GPU development and data processing, and increasing processing speed. Its architecture consists of many layers and hidden variables. Most frequently used algorithms are Deep Neural Networks, Autoencoders and Restricted Boltzmann Machines, which are a derivative of Boltzmann Machines. Deep learning can model complex relations with multilayered structure in place of small structures, ensuring non-linear conversion of data. Deep learning model has increased classification performance because of being advantageous in learning the attributes (Hongli et al., 2015).

Convolutional neural network (CNN): CNN is distinguished in the determination and classification of attributes. The attributes of input data are put forth with the help of convolution process in the structure of deep learning representing advanced level form of convolutional neural networks. Such attributes are conveyed to the next neural layer as input. Corners, folds and such properties appear in such attributes. Deep learning has a multilayered structure and data in each layer is conveyed to the next layer (İnik and Ülker, 2017).

CNNs have several different filter / cores of trainable parameters (randomly initiated) depending on the depth and filters of each layer of network. To capture the true size of a spatial feature by setting the initial values are learned. This high number of filters essentially learns to capture spatial properties from the input volumes based on the learned size. Therefore, they can successfully capture a particular image to a very abstract representation that is easy to predict (LeCun et al., 2015).

In this study, the problem of classifying olive varieties was solved using the convolutional neural networks, which is a deep learning algorithm. The images obtained for four different olive varieties were trained by using convolutional neural network and these were classified as Edremit, Uslu, Domat and Gemlik olive varieties. Afterwards, tests were run with regards to the images in two different data sets that were not included in the training and the results were reported. For classifying the olive varieties, firstly 1000 leaf samples were collected from olive trees of 4 different types from Akhisar-Manisa region. The leaves were photographed on white background from the same angle to take their images. Images for each leaf type were manually annotated. The images were checked and 800 images from each leaf type were selected. 600 of 800 images belonging to same variety were used in the training stage and the remaining 200 were used in the testing stage.

\section{Results and Discussion}

Simple Matching Similarity matrix was used for the determination of genetic similarities of Domat, Uslu, Edremit, Gemlik olive varieties based on ISSR markers and UPGMA dendrogram was obtained (Table 1, Fig. 1).

It was determined that the genetic similarity values of Domat and Uslu olives were closest to each (0.628) other among those olive varieties that were examined based on the matrix data and UPGMA dendrogram and this certifies the fact that origin of both olive varieties was Akhisar- Manisa, (Canözer et al., 1991), and the variety relationship. The application was built in the Python programming language using Keras library, (Erickson et al., 2017), which contains deep learning algorithms.

Classes used for olive leaf classification and their samplesare shownin Fig. 2. The connections among deep convolutional layers and the architecture of classification are included in Fig. 3.

High accuracy rate was obtained in the classification study for olive leaves performed with deep learning. Deep learning algorithm drew a successful image. According to the results, using deep learning algorithm is a correct choice for the determination of olive leaf images. Fig. 4 shows the accuracy

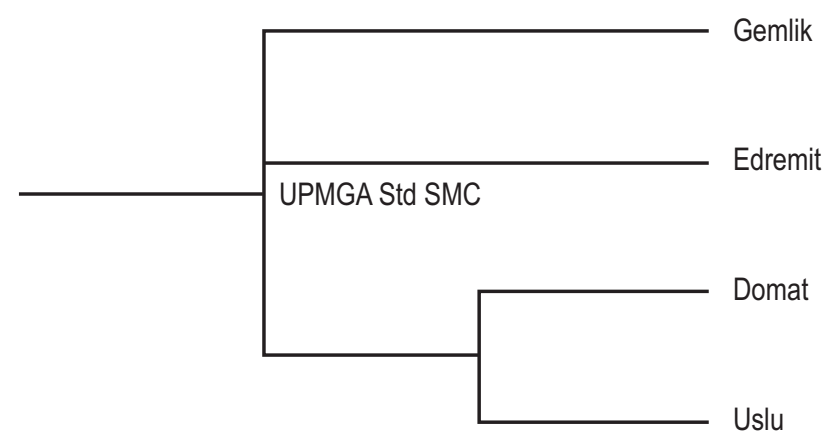

Fig. 1: UPGMA dendrogram. 
Table 1: Genetic similarity matrix Simple Matching Coefficient

\begin{tabular}{lllll}
\hline & Edremit & Gemlik & Domat & Uslu \\
\hline Edremit & 1.000 & & & \\
Gemlik & 0.400 & 1.000 & 1.000 & \\
Domat & 0.486 & 0.457 & 0.628 & 1.000 \\
Uslu & 0.457 & 0.4857 & & \\
\hline
\end{tabular}

Table 2: Confusion matrix

\begin{tabular}{lllllll}
\hline & & Real Value & & \\
\hline & & Edremit & Uslu & Domat & Gemlik & Total \\
\hline Predicted Value & & & & & \\
& Edremit & 44 & 3 & 3 & 2 & 52 \\
& Uslu & 2 & 42 & 2 & - & 46 \\
& Domat & 1 & 2 & 44 & 1 & 48 \\
& Gemlik & 3 & 3 & 1 & 50 & $\mathbf{5 4}$ \\
& Total & $\mathbf{5 0}$ & $\mathbf{5 0}$ & $\mathbf{5 0}$ & $\mathbf{5 0}$ \\
\hline
\end{tabular}

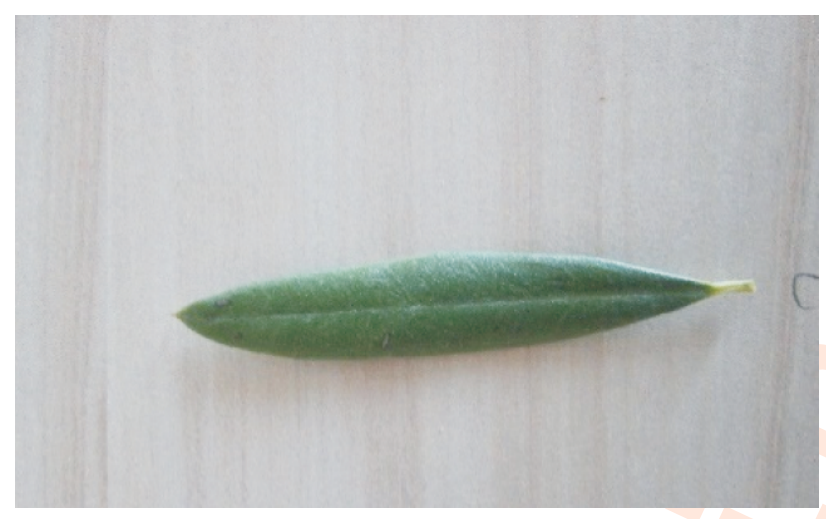

Domat Olive Leaf

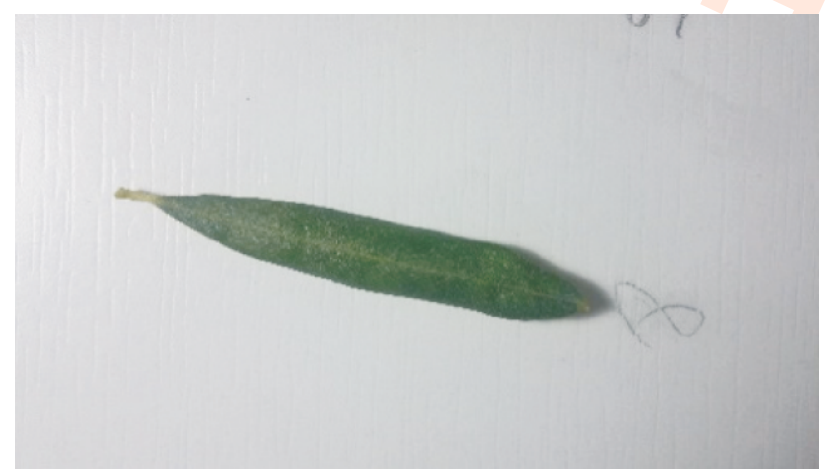

Gemlik Olive Leaf

Fig. 2 : Leaf images.

diagram of deep learning model. Success was obtained at a rate of $89.57 \%$ following the training and testing process consisting twenty-five steps (Barut, 1999; Efe et al., 2013). There are studies on plant leaf classification and identification of leaf diseases that are similar to our study (Sladojevic et al., 2016; Doğan and

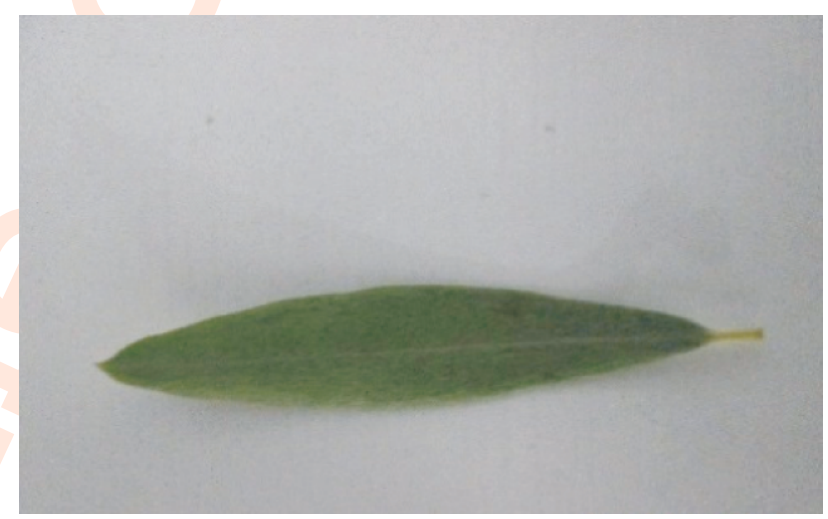

Edremit Olive Leaf

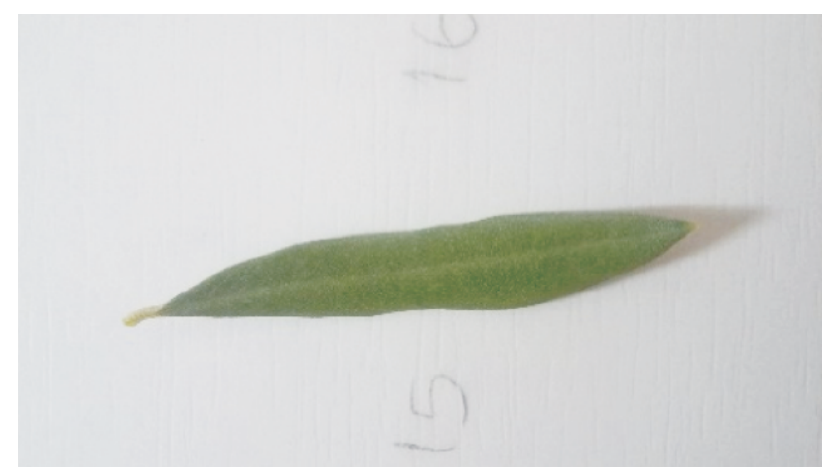

Uslu Olive Leaf

Türkoğlu, 2018). Especially, there have been studies on increasing the success of classification of plant leaves by using different methods. Each study suggested a different approach increasing the success. Pretreatment, different methods for feature extraction and then, artificial neural networks were used in 


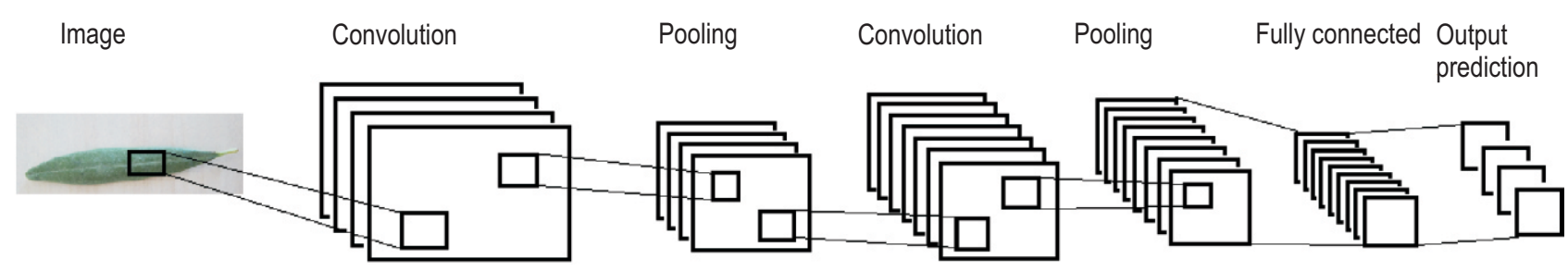

Fig. 3 : Architecture of convolutional neural networks.

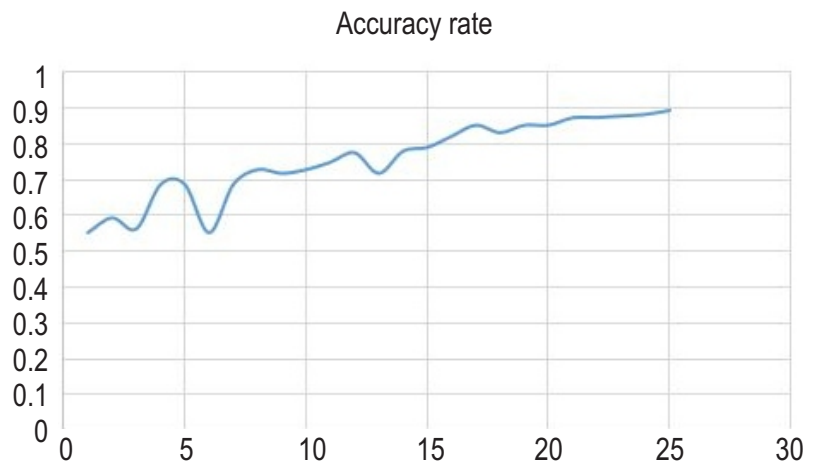

Fig. 4 : Accuracy rate.

almost all studies. Each of these processes are difficult in terms of both time and work load. However, any success over $90 \%$ was considered very important. Many studies show that such rate was between 88 - 97\%. Classifications performed using deep learning algorithms produced better results than many other methods; and it was determined that the success obtained ranged between 97,77 - 99,72\% (Sladojevic et al., 2016; Doğan and Türkoğlu, 2018), these extractions correspond to the success rate that we obtained. The study was conducted on olive leaves. The visuals of some plant leaves can be easily distinguished from each other (Doğan and Türkoğlu, 2018), but olive leaves are very similar. An original aspect of this study is this feature. Leaf samples used in this study consist of only olive leaves and they resemble each other much in shape. The accuracy rate of $89.57 \%$ is very important from this point of view. The Confusion Matrix found according to the results of the model is shown in Table 2. F1 scores of each leaf samples, Edremit 0.85; Uslu 0.86; Domat 0.9 and Gemlik 0.9.

In conclusion, the abundance of olives in terms of variety and factors that some olive varieties resemble each other and some cannot be named correctly in connection to cultivating the same varieties in different environmental conditions, leading to confusion in the definition of varieties sets forth the requirement to find a solution to the problem by using both morphologic and genetic characters together. Deep Learning machine learning is used successfully in many fields recently to support genetic characters that are not affected from environmental conditions; and it provides significant awareness for the classification and identification performed by using morphologic characters affected by environmental conditions.

\section{Acknowledgment}

This study was supported by the Scientific Research Projects Coordination Unit of Manisa Celal Bayar University under Project number: 2010-119.

\section{References}

Barut, E.: Overwiev of olive cultuvars grown in Turkey. Chronica Hort., 39, 23 (1999).

Canözer, Ö. and H. Gökçe: Standard Olive Varieties Catalogue. Ministry of Agriculture and Rural Affairs of Republic of Turkey, Occupational Publications Series No: 334, Serial: 16, Ankara (1991).

Çetin, Ö., A. Mısırlı and M.B. Tanyolaç: Characterization of olive genotypes (Olea europaea L.) by means of DNA markers. Olive Sc., 7, 5-14 (2017).

Doğan, F. and İ. Türkoğlu: Comparison of leaf classification successes of Deep Learning Algorithms. Sakarya Univ. J. Compu. Inform. Sci., (1), Id. Saucis-1-2018, April (2018).

Doyle, J.J. and J.L. Doyle: A rapid DNA Isolation procedure for small quantities of fresh leaftissue. Phytochem. Bull.,19, 11-15 (1987).

Doyle, J.J. and J.L. Doyle: Isolation of plant DNA from fresh tissue. Focus, 12, 13-1 (1990).

Efe, R., A., Soykan, I., Cürebal and S.Sönmez: Olive and olive oil in Edremit Region. Edremit Municipality Publ., p.192 (2013).

Erickson, B.J., P. Korfiatis, Z. Akkus, T. Kline and K. Philbrick: Tool kits and libraries for Deep Learning. J. Digit. Imaging, 30, 400. (2017).

Gupta, P.K. and S. Rustgi: Molecular markers form the transcribed/ expressed region of the genome in higher plants. Funct. Integr. Genom., 4, 139-162 (2004).

Henry, R.J.: Plant genotyping the DNA fingerprinting of plants. CABI Publishing, UK. (2001).

Hongli, D., Y. Tao and G. Jiangjin: An anomaly detection method based on Deep Learning. The Open Autom. Cont. Syst. J., 7, 734-739. (2015).

İnik Ö. And E. Ülker: Deep learning and deep learning models used in image analysis. Gaziosmanpasa J. Sci. Res., 63, 85-104 (2017).

IOOC: World Olive Encyclopedia. International Olive Oil Council, Spain, p. 479 (1997).

Karahan, Ş. and Y.S. Akgül: Eye detection by using Deep Learning. $24^{\text {th }}$ Signal Processing and Communication Application Conference (SIU) (2016)

Le Cun, Y., Y. Bengio and G. Hinton: Deep learning. Nature, 521, 436-444 (2015).

Marmarabirlik. History of Olive. (http://www.marmarabirlikakademi.com/ 
tr/zeytin-kutuphanesi/zeytinin-tarihcesi) (2019).

Ovesna J, K. Polakova and L. Leisova: DNA analyses and their applications in plant breeding. Czech J. Genet. Plant Breed., 38, 29-40. (2002).

Reddy, M.P., N. Sarla and A. Siddiq: Inter simple sequence repeat (ISSR) polymorphism and its application inplant breeding. Euphytica,128, 9-17 (2002).

Sakib, S.Z. Ashrafi and M.A. Siddique: Implementation of fruits recognition classifier using convolutional neural network algorithm for observation of accuracies for various hidden layers. ArXiv, abs/1904.00783 (2019)

Schlüter, P.M. and S.A. Harris: Analysis of multilocus fingerprinting data sets containing missing data. Molec. Ecol. Not., 6, 569-572 (2006).

Sesli, M. and E.D. Yegenoglu: Genetic relationships in wild olives (Olea europaea ssp. oleaster) by ISSR and RAPD markers. Biotechnol. Biotechno. Equip., 31 (2017).

Sladojevic, S., M. Arsenovic, A. Anderla, D. Culibrk and D. Stefanovic:
Deep Neural Networks based recognition of plant diseases by leaf image classification. Computa. Intellig. Neurosci., 2016, Article ID 3289801, 11 pages, (2016).

Sneath, P.H.A and R.R. Sokal: Numerical Taxonomy. San Francisco, Freeman, pp. 230-234 (1973).

Sokal, R.R. and C.D. Michener: A statistical method for evaluating systematic relationships. Univ. Kansas Sci. Bull., 38, 1409-1438 (1958).

UBC: https://patents.google.com/patent/US5989821A/en. (1995).

Vergarı G., M. Patumı and G. Fontanazza: Use of RAPDs Markers in the Characterization of Olive Germplasm. Olivae, 60, 19-22 (1996).

Yegenoğlu, E.D., M. Sesli and Y. Gevrekçi: Determining the genetic relationships between cultivated type olives using ISSR and morphological markers. J. Environ. Biol., 38, 1043-1048 (2017).

Zietkiewicz, E., J.A. Rafalski and D. Labuda: Genome fingerprinting by simple sequence repeat (SSR)-anchored polymerase chain reaction amplification. Genom., 20, 176-183 (1994). 